\title{
Methotrexate in childhood arthritis: effects on gene expression H Moncrieffe ${ }^{* 1}$, S Ursu ${ }^{1}$, A Etheridge ${ }^{1}$, L Kassoumeri ${ }^{1}$, A Stansfield ${ }^{1}$, N Jina ${ }^{2}$ and L Wedderburn ${ }^{1}$
}

\author{
Address: ${ }^{1}$ Rheumatology Unit, Institute of Child Health, UCL, London, UK and ${ }^{2}$ Molecular Haematology and Cancer Biology Unit, Institute of \\ Child Health, UCL, London, UK \\ * Corresponding author
}

\author{
from I5th Paediatric Rheumatology European Society (PreS) Congress \\ London, UK. 14-17 September 2008 \\ Published: 15 September 2008 \\ Pediatric Rheumatology 2008, 6(Suppl I):P22 doi:I0.II86/I546-0096-6-SI-P22
}

This abstract is available from: http://www.ped-rheum.com/content/6/SI/P22

(C) 2008 Moncrieffe et al; licensee BioMed Central Ltd.

\section{Background}

Methotrexate (MTX) is the standard disease modifying therapy for children with juvenile idiopathic arthritis (JIA), inducing remission in $\sim 65 \%$ of cases. There are currently no known predictors which classify who will successfully respond to MTX therapy nor those who will remain well following MTX withdrawal. Mechanisms of MTX action in JIA are at present unclear: genetic and gene expression profiling would provide novel insights into the biology of this therapy.

\section{Materials and methods}

The SPARKS CHARM (Childhood Arthritis Response to Medication) prospective cohort of JIA patients have not received MTX at time of presentation. Peripheral blood mononuclear cells (PBMC) were taken before MTX therapy and at 6 month follow-up. PMBC from another JIA cohort who achieved full remission on MTX were taken at both MTX withdrawal and follow-up. 5 colour flow cytometry and gene expression profiling (Affymetrix) was performed on these samples.

\section{Results}

There are significant differences in gene expression profiles of PBMC of children at time of presentation compared with paired samples at first follow-up. Three important pathways among those implicated are inflammatory cytokines and their signalling pathways, immune cell antigen presentation and apoptosis.

\section{Conclusion}

Gene expression profiling of PBMC provides a valuable insight into the mode of action of MTX. Upon increasing the cohort size, detection of genes predicting response to MTX would then enable appropriate therapy for JIA patients at time of first presentation in the clinic. 